Article

\title{
Analysis of Torque Ripple of a Spoke-Type Interior Permanent Magnet Machine
}

\author{
Guoyu Chu* $*$, Rukmi Dutta $(\mathbb{D}$, Alireza Pouramin and Muhammed Fazlur Rahman $(\mathbb{1}$ \\ School of Electrical Engineering and Telecommunications, UNSW Sydney, Kensington, NSW 2033, Australia; \\ rukmi.dutta@unsw.edu.au (R.D.); pouramin@unsw.edu.au (A.P.); f.rahman@unsw.edu.au (M.F.R.) \\ * Correspondence: g.chu@unsw.edu.au
}

Received: 30 April 2020; Accepted: 29 May 2020; Published: 5 June 2020

check for

updates

\begin{abstract}
This paper investigates the theoretical reasons behind the low torque ripple of a fractional-slot concentrated-winding (FSCW) spoke-type interior permanent-magnet (IPM) machine obtained via a genetic algorithm-based optimization. To better understand the torque performance of the IPMM, this paper uses the frozen permeability method to segregate the overall torque into four components-magnet torque, reluctance torque, cogging torque, and the torque caused by cross-magnetization. Equations and detailed procedures of the torque separation method are discussed in the paper. Analysis of the separated torque components reveals that the counteraction between ripples of different torques leads to the low torque ripple. At high-load conditions, the magnetic saturation alters the torque ripples caused by cross-magnetization to offset ripples of other components resulting in minimization of the overall torque ripple. A detailed parametric analysis of the geometric parameters was carried out to understand their effect in producing minimum torque ripple in the optimized design. In the end, a prototype was built and used for the verification of the torque separation method and the analytical findings based on it.
\end{abstract}

Keywords: FSCW; frozen permeability; finite element; IPMSM; spoke-type; torque separation; torque ripple reduction

\section{Introduction}

In recent times, interior permanent-magnet (IPM) machine has become a viable choice for traction and many other industrial applications due to its advantages of low loss [1], compact size [2], and wide constant power speed range (CPSR) [3]. Among various IPM machine rotor topologies, the spoke-type (I-type) rotors are known for their flux concentration capability from the magnets, which is beneficial for high torque density and high efficiency [4,5]. However, with conventional distributed winding (DW) stators, the I-type rotor could have much higher torque ripple if no special care is taken. In comparison, with a fractional-slot-concentrated-winding (FSCW) stator, a significant reduction of torque ripples was achieved by Pouramin et al. in [6].

Although FSCW I-type machines have the potential to achieve excellent torque performances, finding the optimum design is not easy due to the distorted air-gap magnetic field distribution [7]. Many studies [5-8] attempted to optimize the design to reduce the torque ripple of I-type IPM machines. Performances of FSCW I-type IPM machines with different slot-and-pole combinations were compared and analyzed in $[9,10]$. A large least-common-multiple (LCM) of the number of stator slots and rotor poles reduces the cogging torque [11]. Torque ripple was also minimized by skewing the rotor, altering the magnet configuration, and modifying the rotor shape [5,7]. However, most of these methods could reduce the developed torque while minimizing the torque ripple.

In a recent study, a well-defined finite element model (FEM) based multi-objective optimization procedure was used to reduce the torque ripple without sacrificing torque density in a I-type IPM 
machine [6]. The optimized design achieved a very low torque ripple of $2.49 \%$ at the rated-load condition and a high torque density of $1.5 \mathrm{Nm} / \mathrm{kg}$ (with the current density of $5.7 \mathrm{~A} / \mathrm{mm}^{2}$ ) simply using an FSCW stator. The stator slot and rotor pole numbers were 12 and 10, respectively. Thus, the motor has a relatively large LCM. Moreover, it was found from another work of Pouramin et al. that out of five different rotor topologies with the same LCM, the FSCW I-type rotor consistently produces lower torque ripple [12]. There are well-established theoretical analyses for most of the torque ripple reduction methods, such as rotor skewing, large LCM, and rotor shaping. However, there is no theoretical analysis that could convincingly explain the low torque ripple in the spoke-type FSCW IPM machine. This paper attempts to analyze the torque performance of a spoke-type FSCW IPM machine to understand the theoretical basis. With this objective, this paper analyses the effect of geometric parameters on different torque components and their counteraction relationships in the process of torque ripple formation.

The FEM based frozen permeability method was used in this paper to segregate the magnet, reluctance, and cogging torque components from the overall torque. The frozen permeability method (FPM) is a motor analysis technique which allows the inclusion of magnetic saturation effects in certain analysis, in which otherwise it would be difficult to do so. For example, in a FEM analysis, if magnet needs to be turned off to study the current induced flux linkages, the FPM can be used to include the iron saturation when magnets are present [13]. Chu and Zhu extended the use of FPM to separate average values of various torque components reasonably accurate [14]. Yamazaki and Kumagai included the effect of cross-magnetization in the FPM torque separation [15]. Most recently, the use of the FPM was further extended to study the torque ripple caused by the change in reactive power and due to the hysteretic property of the materials [16]. Based on the new FPM that requires six frozen-permeability simulations (six-time FPM), a procedure to extract torque components with accurate ripple waveforms is presented in Section 3 in this paper. Then, the effect of two critical geometric parameters on the harmonics of each torque component and their influence on counteracting ripples of each other are investigated in Section 4. The parametric analyses showed there exists an optimum geometric design for FSCW I-type IPM machines to achieve very-low torque ripple while maintaining a good torque density. The utilization of the counteraction between torque ripples helped the optimum design to reduce the torque ripple significantly. A prototype of the design and a torque measurement setup were built for experimental verifications. The experimental results proved the reliability of the proposed torque separation method and the analytical findings.

\section{Optimization of the FSCW Spoke-Type IPM Machine}

In the previous study [6], an FSCW spoke-type IPM machine was optimized to achieve smooth torque, high torque density, and wide CPSR using the FE-based non-dominated sorting genetic algorithm (NSGA-II). A detailed description of the optimization process can be found in [6]. This section only briefly introduces the optimization process for the sake of explaining the later analysis.

The 12-slot 10-pole combination was selected for its well-known potential to achieve excellent performances [17]. The designs of trapezoid slots and parallel teeth are selected for the stator, as shown in Figure 1a. Key geometric parameters of the rotor are shown in Figure 1b.

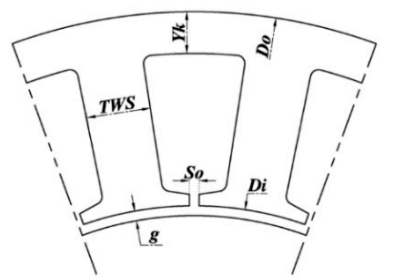

(a)

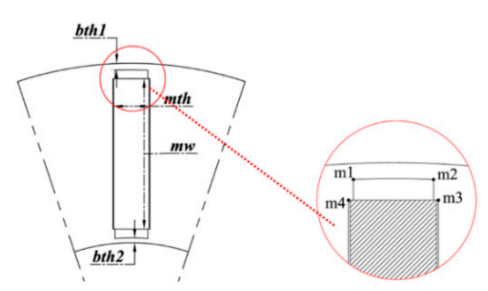

(b)

Figure 1. Parametric models of the FSCW I-type IPM machine that were used in the optimization (a) Model of the stator, (b) model of the rotor. Reprint with permission [6]; 2020, IEEE. 
The stator inner diameter $D i$, stator tooth width TWS, stator yoke width $Y k$, slot-opening width $S o$, magnet thickness $m$ th and width $m w$ were used as design variables. The design objectives are set to maximize efficiency, minimize torque ripple, and minimize the active material cost. The active material cost was defined as:

$$
\text { Active material cost }=C_{p m} w_{p m}+C_{C u} w_{C u}+C_{F e} w_{F e}
$$

where $w_{p m}, w_{C u}$, and $w_{F e}$ are weights of the magnets, copper wires, and steel laminations. $C_{p m}, C_{C u}$, and $C_{F e}$ are unit costs of $\mathrm{NdFeB}$ magnet, copper and electrical steel, respectively. The unit costs were selected as $C_{p m}=26 \$ / \mathrm{kg}, C_{C u}=3 \$ / \mathrm{kg}$ and $C_{F e}=1 \$ / \mathrm{kg}$ based on the market reports [18,19]. Using the minimization of material cost instead of motor weight as an objective could avoid getting a design that uses a large amount of expensive rare-earth material for high torque density. Due to the machine is designed to achieve a wide speed range, the average efficiency of the machine at different speeds, instead of the maximum efficiency, is used for the optimization. For the minimization of the torque ripple, the operating point with rated current magnitude $(I=9.4 \mathrm{~A})$ and the maximum-torque-per-ampere (MPTA) current phase angle $\left(\gamma_{\max }=16.4^{\circ}\right)$ is used for evaluating the torque ripple.

In addition to the objectives, evaluation constraints were set to limit the saturation, demagnetization, and a set value of CPSR. The design used NdFeB-35EH and M400-50A as the material of magnets and electrical steel, respectively. A relatively low current density of $5.7 \mathrm{~A} / \mathrm{mm}^{2}$ was selected because the motor was naturally air-cooled.

After solving 100 candidates per generation for a total of 50 generations, the final design candidate is selected from the Pareto fronts. The optimization used the Transient solver of ANSYS Maxwell 2D because it is generally considered more realistic than the Magnetostatic solver. At full-load condition, the optimized FEM can achieve a very low torque ripple of $1.9 \%$, which can be seen from Figure 2 (Transient FEM). The trends of torque ripple amplitude changing with the current magnitude $I$ and current phase angle $\gamma$ are plotted in Figure $3 a, b$, respectively. Figure 3 shows that the torque ripple amplitude of the optimized machine can be maintained lower than $0.15 \mathrm{Nm}$ for all current magnitudes up to $9.4 \mathrm{~A}$ and current angles up to $50^{\circ}$. This shows that minimizing torque ripple at the operating point with rated current and MPTA current angle could help to control the torque ripple in most of the operating region of the machine. The rest of the key performances and specifications of the selected candidate are listed in Table 1.

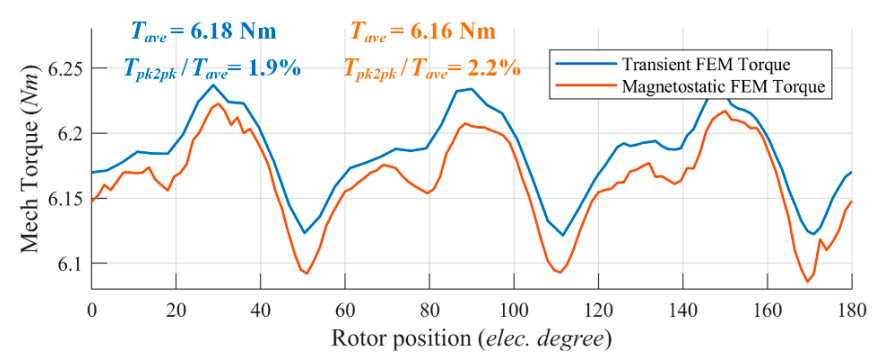

Figure 2. Finite element method (FEM) torques of the optimized FSCW Spoke-type IPM machine.

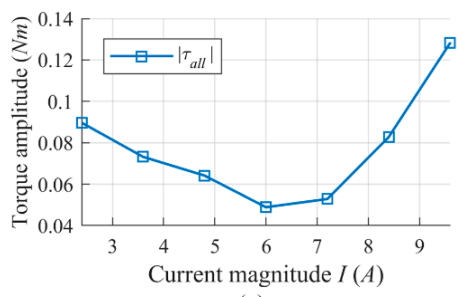

(a)

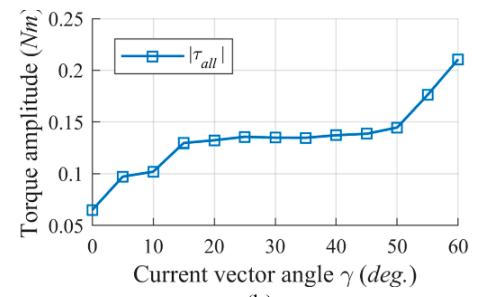

(b)

Figure 3. Torque ripple amplitude changing with (a) current magnitude, (b) current vector angle. 
Table 1. Ratings and key performances of the optimized spoke-type IPM machine design.

\begin{tabular}{ccc}
\hline Ratings/Performance & Units & Value \\
\hline Rated power & $(\mathrm{hp})$ & 1 \\
Base speed & $(\mathrm{rpm})$ & 1155 \\
Max. speed & $(\mathrm{rpm})$ & 5000 \\
Current density & $\left(\mathrm{A} / \mathrm{mm}^{2}\right)$ & 5.7 \\
Torque density & $(\mathrm{Nm} / \mathrm{kg})$ & 1.5 \\
Torque per magnet weight & $(\mathrm{Nm} / \mathrm{kg})$ & 38.48 \\
Efficiency at base speed & $(\%)$ & 85.13 \\
$\gamma_{\text {max }}$ & $(\mathrm{deg})$. & 16.4 \\
Torque ripple & $(\%)$ & 1.9 \\
Saliency ratio & - & 1.34 \\
\hline
\end{tabular}

\section{Torque Ripple Separation Using Frozen Permeability Method}

\subsection{Torque Components}

According to the virtual work principle and law of energy conversion, the torque of a lossless IPM machine can be defined as Equation (2) [20,21].

$$
T=\frac{\partial W_{i n}}{\partial \theta_{M}}-\frac{\partial W_{m g}}{\partial \theta_{M}}
$$

where $\theta_{M}$ is the rotor position (mechanical angle), $W_{i n}$ is the input energy, and $W_{m g}$ is the magnetic energy stored in the machine. The first term in Equation (2) can be further derived as [22]:

$$
T_{i n}=\frac{\partial W_{i n}}{\partial \theta_{M}}=\frac{3}{2} p\left(\psi_{d} i_{q}-\psi_{q} i_{d}+i_{d} \frac{\mathrm{d} \psi_{d}}{\mathrm{~d} \theta_{E}}+i_{q} \frac{\mathrm{d} \psi_{q}}{\mathrm{~d} \theta_{E}}\right)
$$

where $p$ is the pole pairs, $i_{d}$ and $i_{q}$ are the $d, q$ axes currents, $\psi_{d}$ and $\psi_{q}$ are the $d, q$ axes flux linkages, $\theta_{E}$ is the rotor position (electrical angle). Due to the periodical nature of the magnetic field, the second term in Equation (2) and the last two terms in Equation (3) do not appear in the average torque. By neglecting these terms, the classic average torque equation is found as:

$$
T_{d q 0}=\frac{3}{2} p\left(\psi_{d} i_{q}-\psi_{q} i_{d}\right)=\frac{3}{2} p\left(\psi_{m d} i_{q}-\psi_{m q} i_{d}+\left(L_{d}-L_{q}\right) i_{d} i_{q}+L_{d q}\left(i_{q}^{2}-i_{d}^{2}\right)\right)
$$

where $\psi_{m d}$ and $\psi_{m q}$ are the $d$ - and $q$-axis flux linkages generated by the magnets, $L_{d}$ and $L_{q}$ are the self-inductances in the $d-q$ axis frame, $L_{d q}$ is the mutual inductance in the $d-q$ axis frame. Equation (4) is widely used in average torque analysis and FPM based average torque separations $[15,16]$. The four terms on the right-hand side of Equation (4) can be separated as the main magnet torque $T_{m g}$, the magnet torque caused by phase delay $T_{m g_{-} c r}$, the main reluctance torque $T_{r e l}$, and the torque caused by cross-magnetization $T_{\text {rel_cr }}$, sequentially. According to the formation of these components, torque components $T_{m g}$ and $T_{m g_{-} c r}$ are grouped together as the total magnet torque $T_{M G}$; torque components $T_{\text {rel }}$ and $T_{\text {rel_cr }}$ are grouped as the total reluctance torque $T_{R E L}$.

Furthermore, by substituting Equations (3) and (4) into Equation (2), we can get the full torque equation which considers all torque components and torque ripples as:

$$
T=\frac{3}{2} p\left(\psi_{m d} i_{q}-\psi_{m q} i_{d}+\left(L_{d}-L_{q}\right) i_{d} i_{q}+L_{d q}\left(i_{q}^{2}-i_{d}^{2}\right)+i_{d} \frac{d \psi_{d}}{d \theta_{E}}+i_{q} \frac{d \psi_{q}}{d \theta_{E}}\right)-\frac{\partial W_{m g}}{\partial \theta_{M}}
$$

The new terms in Equation (5) are the torque ripples caused by the variation of energies stored in the winding and the magnetic materials, defined as $T_{e n \_} w$ and $T_{e n \_m}$, respectively. In addition, $T_{e n \_} w$ and $T_{e n \_} m$ are not the only two sources of the torque ripple. According to an extended $d-q$ model of FSCW 
IPM machines [23], each of the torque components in Equation (5) has its own harmonics due to the fluctuations in the $d, q$ axes flux linkages, and inductances, which may occur due to magnetic saturation.

\subsection{Frozen Permeability Method}

\subsubsection{Six-Time Frozen Permeability Method}

FPM is a technique for analyzing the performance of an electromagnetic system under individual magnetomotive force (MMF) excitations. Procedures to implement FPM on an IPM machine is shown in Figure 4. In the first step, FPM solves a nonlinear FEM to get permeability data of all mesh elements. Then, the nonlinearity of the magnetic materials can be considered in the simulations by freezing the permeability of the model. In the third step, performances of the IPM machine can be evaluated under the conditions of a single excitation or a combination of multiple selected excitations of $i_{d}, i_{q}$, and magnet [24]. The accuracy of FPM is as good as the accuracy of the nonlinear BH data and mesh quality of the FEM.

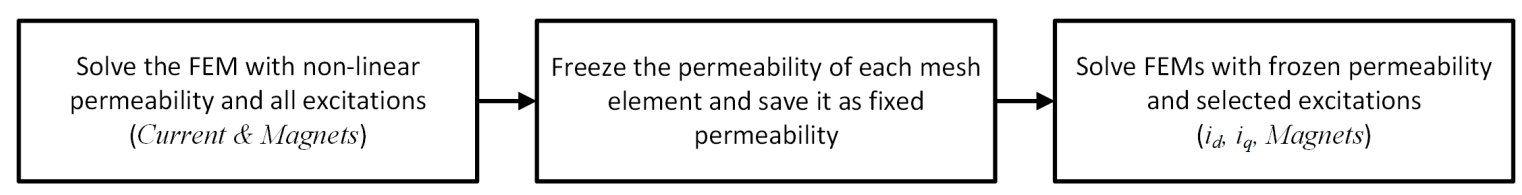

Figure 4. Frozen permeability method procedures.

To extract and analyze all torque components that are mentioned in the previous section, an FPM which requires six frozen permeability computations are used in this section [16]. Excitations applied in these six frozen permeability computations (six-time FPM) are listed in Table 2.

Table 2. MMF excitations of the six-time frozen permeability method (FPM).

\begin{tabular}{ccccc}
\hline \multirow{2}{*}{ FPM Number } & \multicolumn{3}{c}{ Normalized Excitations } & \multirow{2}{*}{ FPM Torques } \\
\cline { 2 - 4 } & $\boldsymbol{i}_{\boldsymbol{d}}$ & $\boldsymbol{i}_{\boldsymbol{q}}$ & Magnets & \\
\hline 1 & 0 & 0 & 1 & $T_{(m)}$ \\
2 & 1 & 0 & 1 & $T_{\left(m, i_{d}\right)}$ \\
3 & 0 & 1 & 1 & $T_{\left(m, i_{q}\right)}$ \\
4 & 1 & 1 & 0 & $T_{\left(i_{d}, i_{q}\right)}$ \\
5 & 1 & 0 & 0 & $T_{\left(i_{d}\right)}$ \\
6 & 0 & 1 & 0 & $T_{\left(i_{q}\right)}$ \\
\hline
\end{tabular}

In this study, the FPM is implemented in ANSYS Maxwell 2D Magnetostatic model. According to the ANSYS Maxwell Training Manual [25], the Magnetostatic solver only solves static magnetic field excited by DC currents, and hence, cannot consider any time-varying terms in the torque Equation (5), such as $\mathrm{d} \psi_{d} / \mathrm{d} \theta_{E}$ and $\mathrm{d} \psi_{q} / \mathrm{d} \theta_{E}$. Thus, the torque equation for a Magnetostatic model needs to be rewritten from Equation (5) to:

$$
T=\frac{3}{2} p\left(\psi_{m d} i_{q}-\psi_{m q} i_{d}+\left(L_{d}-L_{q}\right) i_{d} i_{q}+L_{d q}\left(i_{q}^{2}-i_{d}^{2}\right)\right)-\frac{\partial W_{m g}}{\partial \theta_{M}}
$$

In Equation (6), the torque component $T_{e n_{-} w}$ is neglected. However, the torque waveform generated by the Magnetostatic solver and Transient solver is fairly consistent with an error of $0.3 \%$, as seen in Figure 2. Hence, it can be concluded that the Magnetostatic solver is adequately accurate for analyzing the torque performances of the machine. The following sections will use the Magnetostatic FEM and its simplified torque Equation (6) for the torque performance analysis. 
Based on the excitation source, the magnetic energy stored in the machine can be decomposed into the three terms as in Equation (7).

$$
W_{m g}\left(i_{d}, i_{q}, M\right)=W_{m g}\left(i_{d}, 0,0\right)+W_{m g}\left(0, i_{q}, 0\right)+W_{m g}(0,0, M)=W_{m g-i_{d}}+W_{m g_{-} i_{q}}+W_{m g \_} M
$$

where $M$ represents the excitation of the permanent magnets, $W_{m g_{-} i_{d}}$ is the stored energy due to the $i_{d}$, $W_{m g_{-} i_{q}}$ is the stored energy due to the $i_{q}, W_{m g_{-} M}$ is the stored energy due to the permanent magnets.

The stored energies of $W_{m g_{-} i_{q}}, W_{m g_{-} i_{d}}, W_{m g_{-} M}$ vary with the current phase and rotor position, and hence, generates periodical torque ripples. Based on Equations (6) and (7), the FPM calculated six torques according to excitations of Table 2 can be derived as:

$$
\begin{gathered}
T_{(m)}=-\frac{\partial W_{m g_{-} M}}{\partial \theta_{M}} \\
T_{\left(m, i_{d}\right)}=\frac{3}{2} p\left(-\psi_{m q} i_{d}-L_{d q} i_{d}^{2}\right)-\frac{\partial W_{m g_{-} i_{d}}}{\partial \theta_{M}}-\frac{\partial W_{m g_{-} M}}{\partial \theta_{M}} \\
T_{\left(m, i_{q}\right)}=\frac{3}{2} p\left(\psi_{m d} i_{q}+L_{d q} i_{q}^{2}\right)-\frac{\partial W_{m g_{-} i_{q}}}{\partial \theta_{M}}-\frac{\partial W_{m g_{-} M}}{\partial \theta_{M}} \\
T_{\left(i_{d}, i_{q}\right)}=\frac{3}{2} p\left(\left(L_{d}-L_{q}\right) i_{d} i_{q}+L_{d q}\left(i_{q}^{2}-i_{d}^{2}\right)\right)-\frac{\partial W_{m g_{-} i_{d}}}{\partial \theta_{M}}-\frac{\partial W_{m g_{-} i_{q}}}{\partial \theta_{M}} \\
T_{\left(i_{d}\right)}=-\frac{3}{2} p L_{d q} i_{d}^{2}-\frac{\partial W_{m g_{-} i_{d}}}{\partial \theta_{M}} \\
T_{\left(i_{q}\right)}=\frac{3}{2} p L_{d q} i_{q}^{2}-\frac{\partial W_{m g_{-} i_{q}}}{\partial \theta_{M}}
\end{gathered}
$$

Thus, the total output torque $T$ can be represented by the six torque component as [16]:

$$
T_{\text {six }}=T=T_{\left(i_{d}, i_{q}\right)}+T_{\left(m, i_{d}\right)}+T_{\left(m, i_{q}\right)}-T_{\left(i_{d}\right)}-T_{\left(i_{q}\right)}-T_{(m)}
$$

Figure 5a compares the overall torque $T_{\text {six }}$ obtained by summing the six torque components of Table 2 with the torque obtained from Transient FEM solver $T_{F E A}$. It can be seen that $T_{\text {six }}$ and $T_{F E A}$ are fairly similar, and both predict very similar torque ripples. This proves that the six-time method is reasonably accurate for calculating the torque ripples. The FPM calculated torque component $T_{\left(m, i_{q}\right)}$ is plotted in Figure 5a. Torque components that are lower than $1 \mathrm{Nm}$ are plotted in Figure $5 \mathrm{~b}$ with a different $y$-axis to make the fluctuations more visible to show the zoomed in details.

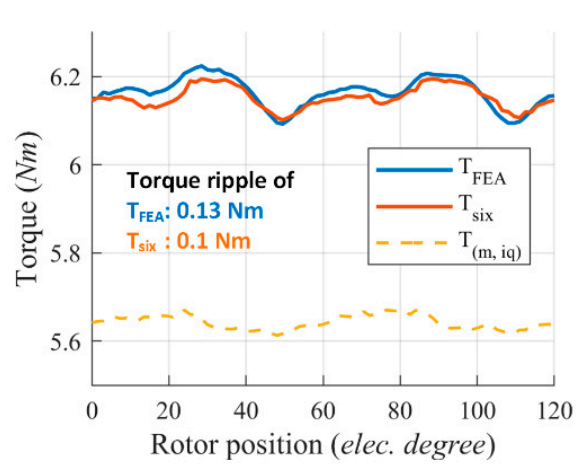

(a)

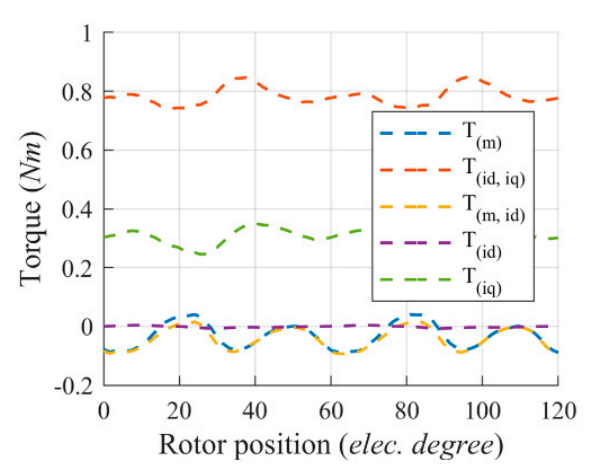

(b)

Figure 5. Torques calculated using the six-time FPM. (a) Torque curves of the $T_{F E A}, T_{s i x}$, and $T_{\left(m, i_{q}\right)}$. (b) Torques that are lower than $1 \mathrm{Nm}$, i.e., $T_{(m)}, T_{\left(i_{d}, i_{q}\right)}, T_{\left(m, i_{d}\right)}, T_{\left(i_{d}\right)}$ and $T_{\left(i_{q}\right)}$. 


\subsubsection{Separation of Torque Components}

Cogging torque of an IPM machine is produced by the interaction between magnets and the uneven reluctance distribution of the stator. Thus, for the calculation of cogging torque, a magnet-only excitation is required. From the law of energy conversion, the cogging torque is defined as:

$$
T_{c o g}=T_{(m)}=-\frac{\partial W_{m g_{-} M}}{\partial \theta_{M}}
$$

We can see from Figure $5 b$ that the cogging torque calculated using the FPM has a small DC offset. Since the FPM can consider the saturation effect at loaded conditions, the saturation effect could be the main reason that $T_{\operatorname{cog}}$ has a DC offset in Figure $5 \mathrm{~b}$. This conclusion will be confirmed later by Figure 16 in Section 5.

By substituting Equations (8)-(13) into Equations (5) and (6), other torque components can be obtained as:

$$
\begin{gathered}
T_{m g}=T_{\left(m, i_{q}\right)}-T_{\left(i_{q}\right)}-T_{(m)}=\frac{3}{2} p \psi_{m d} i_{q} \\
T_{m g_{-} c r}=T_{\left(m, i_{d}\right)}-T_{\left(i_{d}\right)}-T_{(m)}=-\frac{3}{2} p \psi_{m q} i_{d} \\
T_{r e l}=T_{\left(i_{d}, i_{q}\right)}-T_{\left(i_{d}\right)}-T_{\left(i_{q}\right)}=\frac{3}{2} p\left(\left(L_{d}-L_{q}\right) i_{d} i_{q}\right) \\
T_{r e l_{-} c r}^{\prime}=T_{\left(i_{d}\right)}+T_{\left(i_{q}\right)}=\frac{3}{2} p L_{d q}\left(i_{q}^{2}-i_{d}^{2}\right)-\frac{\partial W_{m g_{i_{d}}}}{\partial \theta_{M}}-\frac{\partial W_{m g_{i_{q}}}}{\partial \theta_{M}}
\end{gathered}
$$

The torque components $T_{\text {rel_cr }}$ and $T_{e n \_}\left(i_{d}, i_{q}, 0\right)$ have the same excitations, and hence, they cannot be separated from each other using FPM. Therefore, in this study, these two torque components are added together as $T_{r e l \_c r}^{\prime}$.

\subsubsection{Extraction of Magnet Flux Linkage Components $\psi_{m d}$ and $\psi_{m q}$}

Conventionally, the $\psi_{m d}$ and $\psi_{m q}$ are calculated from a frozen permeability simulation with $I_{d}=I_{q}=0$. It assumes the flux linkage of a frozen permeability model, which only has the excitation of magnets, is the same with flux linkage generated by the magnets of a model with full excitations. Then, $\psi_{m d}$ and $\psi_{m q}$ can be obtained by performing a $d-q$ transformation to the 3-phase flux linkages. However, it was found that the $\psi_{m d}$ and $\psi_{m q}$ obtained by the conventional method cannot reproduce torque ripples of the magnet torque $T_{M G}$ accurately, as shown in Figure 6.

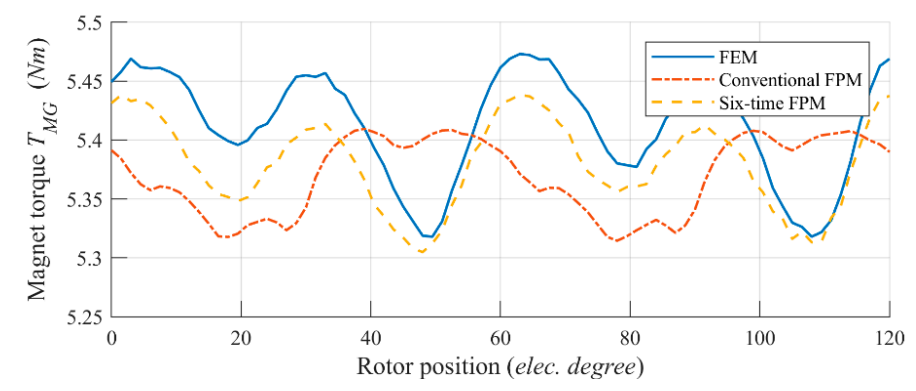

Figure 6. Magnet torque $T_{M G}$ calculated by FEM, conventional FPM, and six-time FPM.

Alternatively, flux linkage components $\psi_{m d}$ and $\psi_{m q}$ can be extracted from the torques calculated using the six-time FPM as below:

$$
\psi_{m d_{-} s i x}=T_{m g} /\left(\frac{3}{2} p i_{q}\right)=\frac{2}{3}\left(T_{\left(m, i_{q}\right)}-T_{\left(i_{q}\right)}-T_{(m)}\right) /\left(p i_{q}\right)
$$




$$
\psi_{m q_{-} s i x}=-T_{m g_{-} c r} /\left(\frac{3}{2} p i_{d}\right)=-\frac{2}{3}\left(T_{\left(m, i_{d}\right)}-T_{\left(i_{d}\right)}-T_{(m)}\right) /\left(p i_{d}\right)
$$

The magnet torque reproduced using the $\psi_{m d_{-} \text {six }}$ and $\psi_{m q_{-} \text {six }}$ of Equations (20) and (21) matches more closely to $T_{M G}$ obtain from the FEM. Although the average magnet torque calculated by all three methods are fairly similar, the torque ripple patterns of the six-time FPM matches more closely to the FEM result. The waveform of the conventional FPM is quite different from the FEM result. This indicates that the $d-, q$-axes flux linkages of a magnet-only frozen permeability model (conventional FPM) have similar zero-sequence components with the $\psi_{m d}$ and $\psi_{m q}$ of a fully excited FEM, but the harmonics and waveforms are not the same.

\section{Analysis of Torque Ripple Components}

\subsection{Analysis of the Torque Ripples of the Optimized Design}

This section focuses on the analysis of the torque ripples. Therefore, the average value of each torque component is removed in the following analysis.

To distinguish the torque ripple components from the torque components mentioned in the previous section, the letter $\tau$ is used. For example, the torque ripple of the main magnet torque $T_{m g}$ is represented by $\tau_{m g}$; torque ripple of the total torque $T_{F E A}$ is represented by $\tau_{\text {all }}$.

$$
\begin{gathered}
\tau_{m g}=T_{m g}-\operatorname{mean}\left(T_{m g}\right) \\
\tau_{\text {all }}=T_{F E A}-\operatorname{mean}\left(T_{F E A}\right)
\end{gathered}
$$

Figure 7 shows the torque ripples of the key torque components. It is very difficult to see any clear pattern in Figure 7a. However, if the ripples are separated into two groups, an obvious counteraction between these two groups can be observed, as in Figure $7 \mathrm{~b}$. The first group of Figure $7 \mathrm{~b}$ was formed by summing the magnet and reluctance torque ripples $\left(\tau_{m g}+\tau_{r e l}\right)$, whereas the other group was formed by summing the ripples of the remaining components $\left(\tau_{m g_{-} c r}+\tau_{\text {rel_cr }}^{\prime}+\tau_{c o g}\right)$. The counteraction between these two groups reduced the overall peak-to-peak torque ripple by $40 \%$ compared to the ripple of $\left(\tau_{m g}+\tau_{r e l}\right)$. It can be concluded from this observation that torque ripple due to the cross-magnetization effect and cogging torque could contribute to the reduction of torque ripple if the machine was properly optimized.

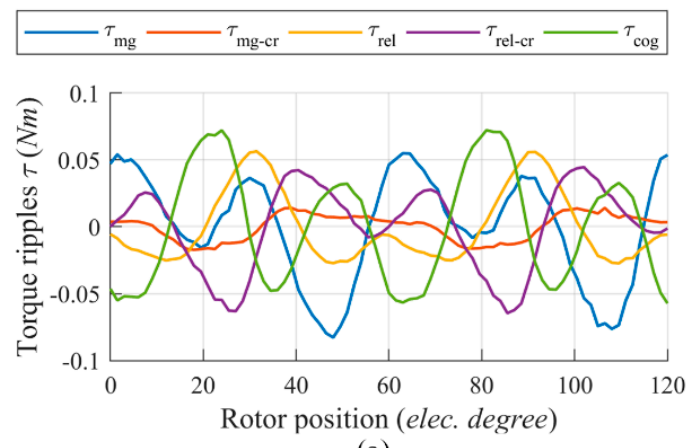

(a)

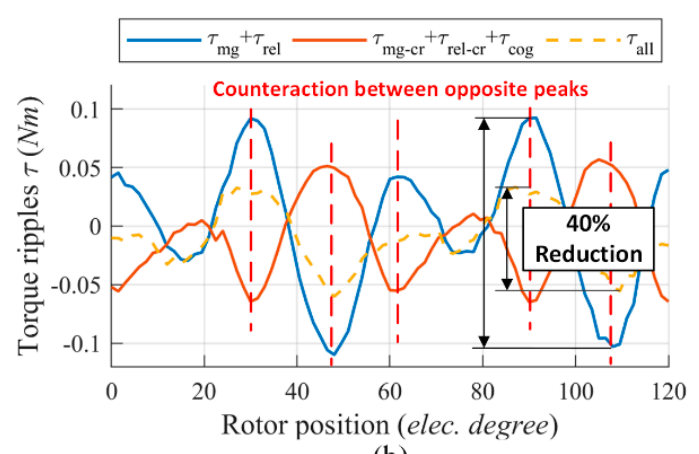

(b)

Figure 7. (a) Separated torque ripples. (b) Counteraction between re-grouped torque ripples.

\subsection{Parametric Analysis of the Torque Ripple Components}

\subsubsection{Harmonics of the Torque Ripple}

This section investigates the effect of geometric parameters selected by the optimization algorithm on the torque ripple. Fast Fourier transformation was carried out on the key torque ripple components- $\tau_{\text {all }}, \tau_{M G}, \tau_{R E L}$, and $\tau_{\operatorname{cog}}$. Figure 8 a shows amplitudes of the first four harmonics 
of $\tau_{\text {all }}, \tau_{M G}, \tau_{R E L}$, and $\tau_{c o g}$. It can be seen that the first two harmonics were dominant. Therefore, only the 1st and 2 nd harmonics were considered in the following analysis. These two harmonics are referred to as $h 1$ and $h 2$, respectively. Although some details are neglected, the first two harmonics were still adequate to reproduce the main characteristics of the torque ripple. Because the torque ripples repeated in every $1 / 6$ of the electrical period, $h 1$ and $h 2$ also corresponded to the 6 th and 12 th order harmonics in the Fourier spectrum of the torque across one electrical period. According to Figure $8 b$, the phase difference between the 1 st harmonics of $\tau_{m g}$ and $\tau_{r e l}$ was $185^{\circ}$; the phase difference between the 2nd harmonics of $\tau_{r e l}$ and $\tau_{c o g}$ was around $195^{\circ}$. Therefore, these harmonics could offset each other in pairs to minimize their contribution to the overall torque ripple.

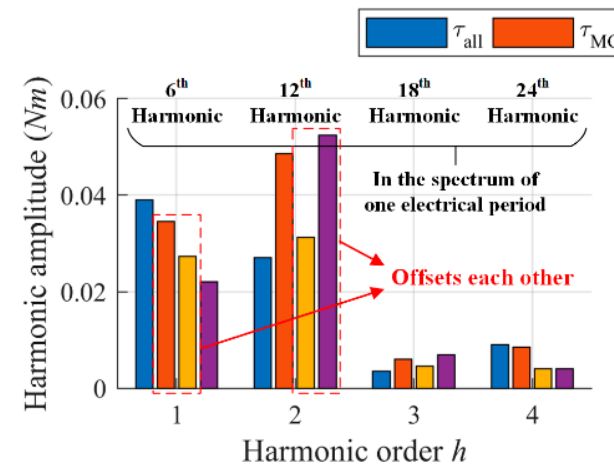

(a)

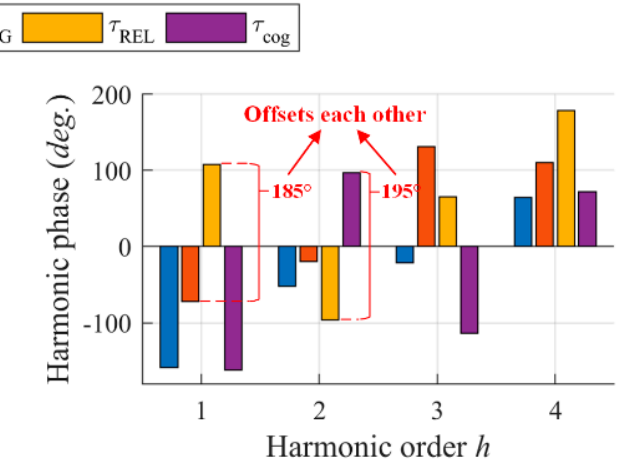

(b)

Figure 8. Harmonics of the key torque ripple components: (a) harmonic amplitudes and (b) harmonic phase angles.

\subsubsection{Effect of Geometric Parameters on the Amplitude of Torque Ripples}

In torque ripple and cogging torque analyses, pole-pitch width and slot-opening width are the two most important parameters [26]. However, the pole-pitch of a spoke-type IPM machine is unique compared to other IPM machine rotor topologies. In spoke-type topology, the magnet width $m$ th affects the ripple and cogging torque more than the pole-pitch itself. Hence, the sensitivity of variation of $m$ th on the ripple was studied along with the sensitivity of variation of slot opening width So.

First, a parametric analysis of the harmonics of $\tau_{\text {all }}$ was performed. Responses of the harmonics to the variations of $m$ th and $S o$ are plotted in Figures $9 \mathrm{a}, \mathrm{b}$, respectively. In these two figures, $\left|\tau_{\text {all }}\right|$ represents the amplitude of $\tau_{\text {all }} ;|h 1|$ is the amplitude of $h 1$ of $\tau_{\text {all }} ;|h 2|$ is the amplitude of $h 2 ;|h 1|+|h 2|$ is the summation of the amplitudes of $h 1$ and $h 2$.

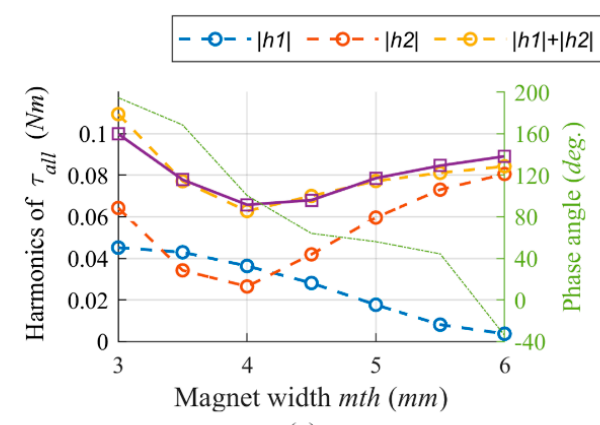

(a)

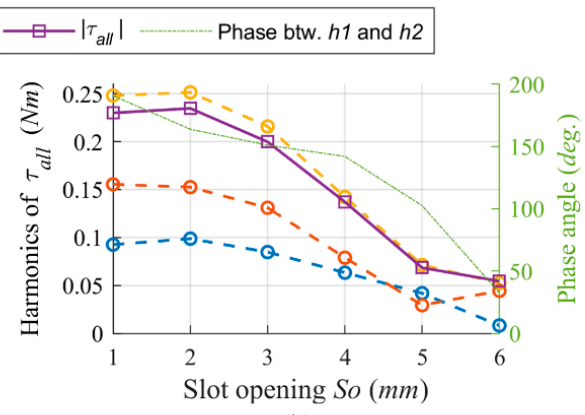

(b)

Figure 9. Parametric analysis of $\tau_{\text {all }}$ with variations of (a) magnet width $m$ th, (b) slot-opening So.

It can be seen from Figure 9a that $\left|\tau_{\text {all }}\right|$ changed with $m$ th in the form of a convex curve. At the lowest point of the convex curve, we can get $m \mathrm{th}=4 \mathrm{~mm}$ and $\left|\tau_{\text {all }}\right|=0.066 \mathrm{Nm}$ for the investigated design. This point is the optimum option for getting the minimum torque ripple, which was also 
selected by the optimization algorithm for the studied IPM machine design. From Figure $9 b$, it can be seen that $\left|\tau_{\text {all }}\right|$ had a decreasing trend with increasing slot opening, i.e., a larger slot opening resulted in lower torque ripple amplitude. The minimum torque ripple was found at the largest value of $S o=6 \mathrm{~mm}$. However, the optimization algorithm selected a slot-opening width of $5 \mathrm{~mm}$ for the design. This is because further increasing So would become not worth the tradeoff of average torque. To minimize torque ripple without sacrificing average torque (as set by the objective and constraints), the genetic algorithm selected a slot-opening at which the decreasing slope of $\left|\tau_{\text {all }}\right|$ starts to be flat. Moreover, it can be observed from Figure 9 that $|h 1|+|h 2|$ was always in a good agreement with the amplitude of $\tau_{\text {all }}$ although the phase difference between $h 1$ and $h 2$ varied more than $180^{\circ}$. This shows that, in this case, the phase difference between the harmonics ( $h 1$ and $h 2)$ had very little effect on the amplitude of the torque ripple.

Next, the trends of $\left|\tau_{M G}\right|,\left|\tau_{R E L}\right|$, and $\left|\tau_{c o g}\right|$ changing with $m$ th and So are plotted in Figure 10a,b, respectively. By observing the plots, we can find that increasing magnet width $m$ th reduced the amplitudes of both $\tau_{M G}$ and $\tau_{c o g}$; increasing slot-opening So reduced the amplitude of $\tau_{M G}$. An interesting finding from Figure $10 \mathrm{~b}$ is that increasing the slot-opening width did not always reduce the cogging torque like most cases of DW IPM machine. The trajectory of $\left|\tau_{c o g}\right|$ varying with So was a concave curve. The highest cogging torque occurred in the middle of the feasible region of So. Moreover, $\left|\tau_{R E L}\right|$ only changed around $0.01 \mathrm{Nm}$ with the variation of geometry in this parametric analysis. The amplitude of the reluctance torque ripple was not as sensitive to the parametric variation as the other two ripple components.

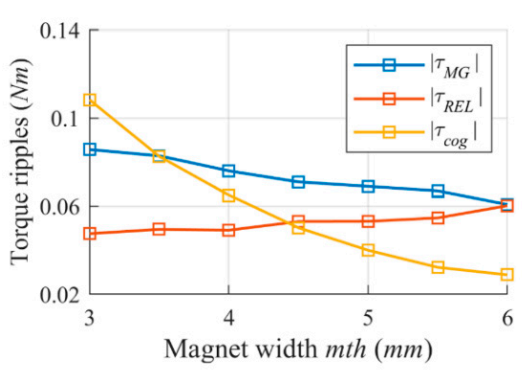

(a)

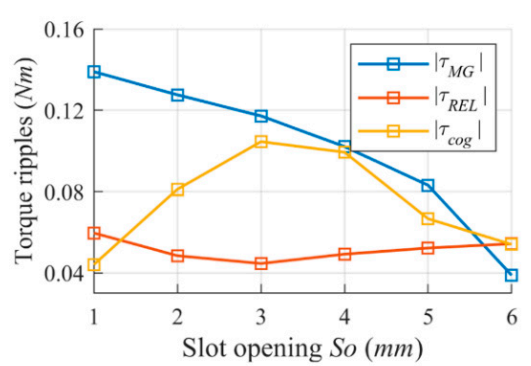

(b)

Figure 10. Parametric analysis of $\tau_{M G}, \tau_{R E L}, \tau_{\operatorname{cog}}$ with variations of (a) magnet width $m$ th, (b) slot-opening So.

\subsubsection{Effect of Geometric Parameters on the Relative Phase Angle between Torque Ripples}

This section investigates the effect of geometric parameters on the relative phase angle between torque ripples. Figure 11 shows that $m$ th and So had significant effects on the relative phase angle between harmonics of the same order.

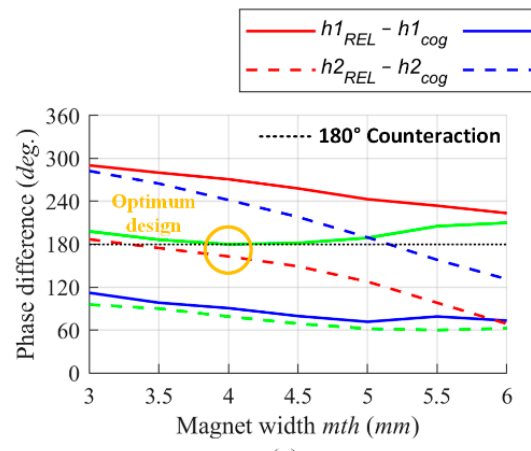

(a)

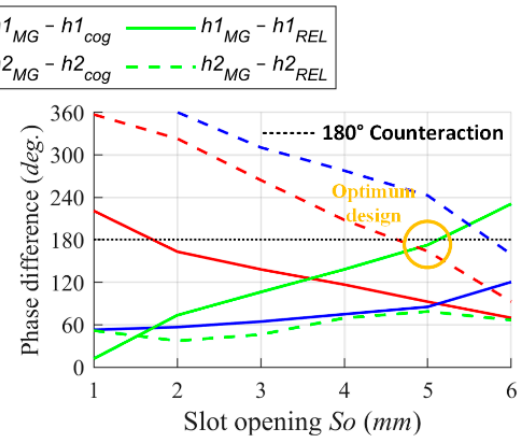

(b)

Figure 11. Phase difference of harmonics of $\tau_{M G}, \tau_{R E L}, \tau_{\operatorname{cog}}$ with variations of (a) magnet width $m$ th, (b) slot-opening So. 
As found from the analysis of Figure $8 \mathrm{~b}$, the optimized design has two pairs of harmonics, $h 1_{M G}-h 1_{R E L}$ and $h 2_{R E L}-h 2_{\operatorname{cog}}$, that are aligned to each other with a relative angular difference very close to $180^{\circ}$. Figure 11 shows the same phenomenon when $m \mathrm{th}=4 \mathrm{~mm}$ and $S o=5 \mathrm{~mm}$. By observing the torque curves of Figures 8-11 together, we can find that simply reducing the amplitude of individual torque ripple components may not minimize the total ripple. Achieving a near phase opposite condition between torque harmonics is as critical as reducing their amplitudes for the total torque ripple reduction.

\subsubsection{Comparison of the Worst-Case Designs with the Optimum Design}

To show the effect of the geometric parameters on torque ripples more intuitively, the torque ripple waveforms of the worst-case designs were compared with the optimum design torque ripples in Figure 12. Figure 12a shows the waveforms of the grouped torque ripple $\tau_{M G}+\tau_{R E L}$ and $\tau_{c o g}$ of the optimum design. Although the grouping method is not the same with Figure $7 \mathrm{~b}$, peaks of the two waveforms are still aligned oppositely.

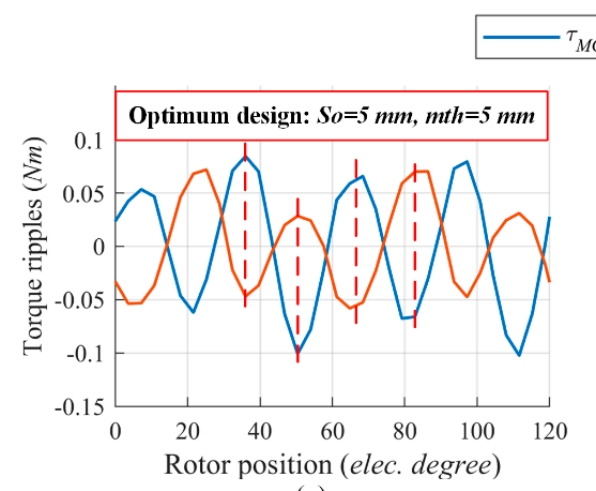

(a)

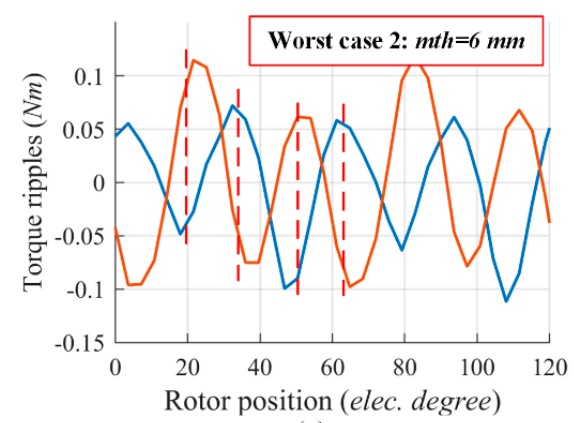

(c)

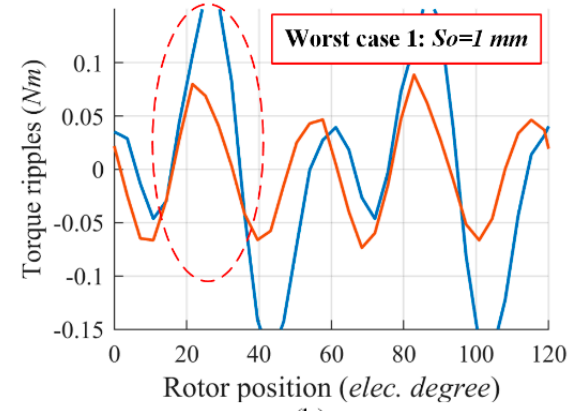

(b)

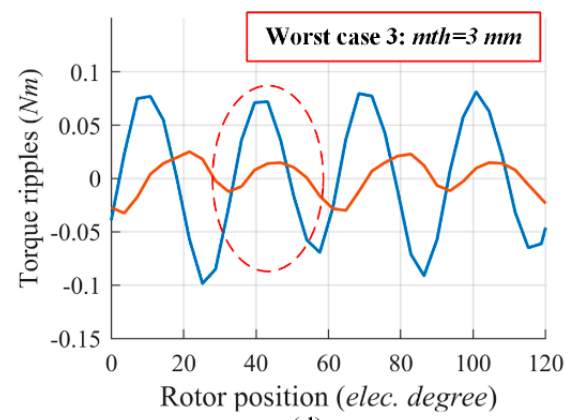

(d)

Figure 12. Torque ripple waveforms of: (a) the optimum design, worst-case designs with (b) So $=1 \mathrm{~mm}$, (c) $m \mathrm{th}=6 \mathrm{~mm}$, and (d) $m \mathrm{th}=3 \mathrm{~mm}$.

According to Figure 9, the worst-case of the parametric analysis occurred when the slot-opening reduces to the minimum value, $S o=1 \mathrm{~mm}$. Therefore, $\tau_{M G}+\tau_{R E L}$ and $\tau_{\operatorname{cog}}$ of the design with $S o=1 \mathrm{~mm}$ are calculated and plotted in Figure 12b. In comparison with the optimum design, the cogging torque ripple $\tau_{\operatorname{cog}}$ did not change obviously; the amplitude of $\tau_{M G}+\tau_{R E L}$ became more than 1.6 times large of the optimum design. Most importantly, the phase position of $\tau_{M G}+\tau_{R E L}$ was shifted in a way that torque ripple peaks of the same polarity are aligned together, which worsened the total torque ripple significantly.

According to Figure 9 a, the trend of $\left|\tau_{\text {all }}\right|$ changing with $m$ th is a convex curve. Both designs at the two ends of the curve had higher $\left|\tau_{\text {all }}\right|$ than the optimum design. To understand the convex shape of the curve, values of $m$ th at the two ends of the curve $(m \mathrm{th}=3 \mathrm{~mm}$ and $m \mathrm{th}=6 \mathrm{~mm}$ ) were used to plot the torque ripple waveforms in Figure 12c,d, respectively. In Figure 12c, the design with $m$ th increased to 
the maximum limit of $6 \mathrm{~mm}$ had a slightly shifted phase alignment comparing to the optimum design. Hence, the cancellation between different torque ripples was weakened. In addition, the significant increase in the amplitude of the cogging torque changed the balance between different torque ripples, which caused a further increase in the total output torque ripple. In Figure 12d, the amplitude of cogging torque reduced to half of the optimum design, but the peaks of $\tau_{M G}+\tau_{R E L}$ and $\tau_{\operatorname{cog}}$ were no longer oppositely aligned. Consequently, the amplitude of total torque ripple also increased in this case. The changes of torque ripple amplitude and phase angle that are shown in Figure 12 confirmed the changing trend of torque ripples shown in Figures 9 and 10.

\section{Experimental Verifications}

To validate the performance of the optimized design, a 1:1 scaled prototype was built, as shown in Figure 13a. Detailed test results of the prototype can be found in the previous literature [6]. This study focused on using the prototype to verify the torque separation method used in this study and the analysis based on its results. It should be noted that the torque ripple analyzed in this paper all originated from electromagnetic effects only. However, in a real machine, additional torque ripple can appear due to other system non-linearities such as bearing, friction, loading system, etc. Hence, a standstill method described in a recent study of Pouramin et al. [27], was used to measure the electromagnetic torque ripples in this study. The experimental setup is shown in Figure 13b. Instead of having two motors coupled back-to-back via a torque transducer, a lock system was used to lock the motor at different rotor positions when the stator was excited with the rated current. The torque transducer measured the induced electromagnetic torque at various positions. The plotting of the measured torque versus the rotor position gave the electromagnetic torque profile. In addition, because the torque was measured at the stationary condition with only DC excitations, the measurements were not affected by any time-vary factors such as $\mathrm{d} \psi / \mathrm{d} t$. Equation (5) is also applicable to the measured torques.

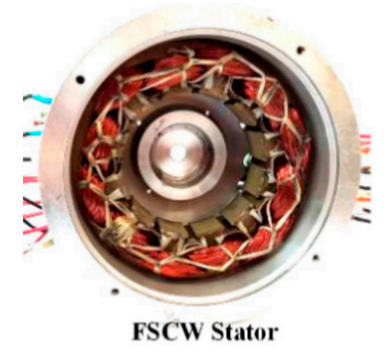

(a)

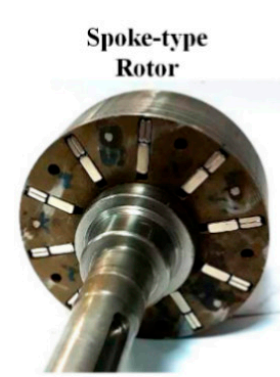

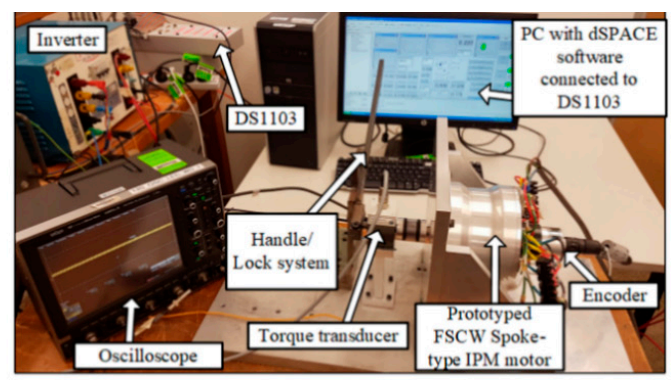

(b)

Figure 13. (a) Stator and rotor of the prototype. (b) Standstill torque measurement setup with a torque transducer and handle lock system. Reprint with permission [6]; 2020, IEEE.

Figure 14 compares the measured torques with the six-time FPM and the Magnetostatic FEM results for the rated operation condition. The measured torque was in a high agreement with the FEM. The measured torque ripple $\left|\tau_{\text {Exp }}\right|$ was around $2.5 \%$, while that of the FEM $\left|\tau_{F E A}\right|$ was about $2.2 \%$. We found that the results of six-time FPM were also in good agreement with the experimental measurements. Despite being distorted slightly from the experimental results, the position of ripple peaks, fluctuation pattern, and torque ripple amplitude of $T_{s i x}$ were very close to the experimental results. It had a torque ripple percentage of $\left|\tau_{S i x}\right|=2.7 \%$, which was closer to the experimental result than the FEM result of $\left|\tau_{F E A}\right|$. Hence, we can conclude that the six-time FPM is fairly accurate for predicting the total output torque of an IPM machine. 


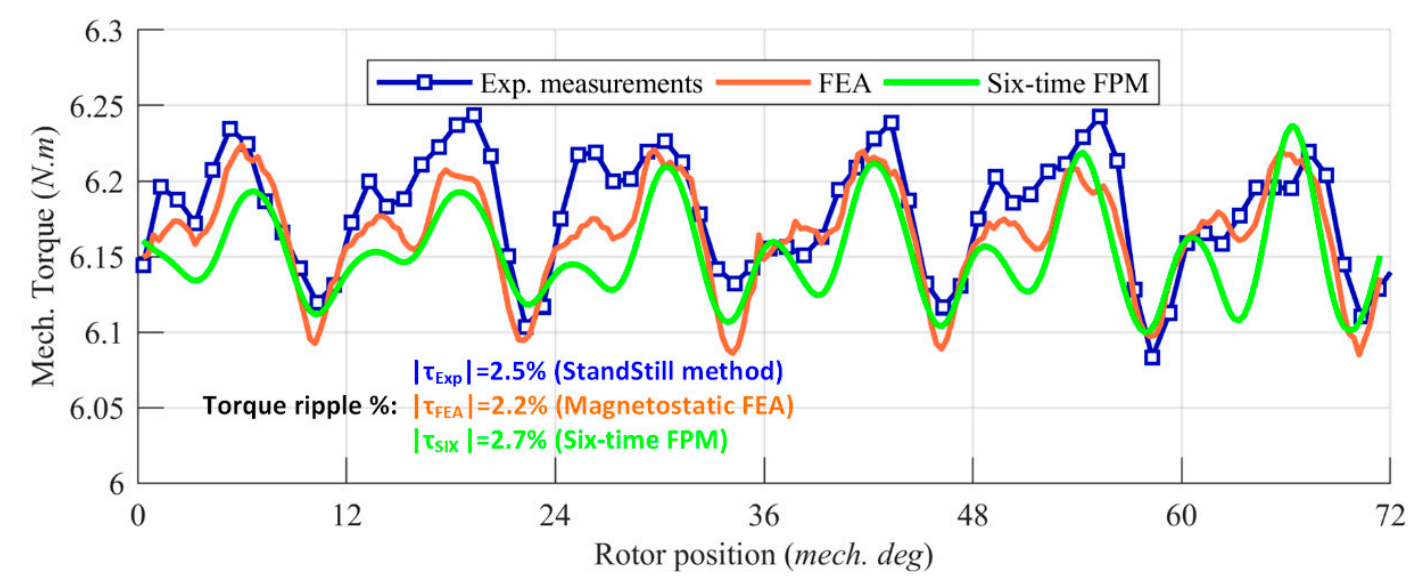

Figure 14. Comparison of the torque waveform obtained from experimental measurements with the FEM results for the rated operating condition (1155 rpm, $750 \mathrm{~W})$.

The back-EMF of the prototype at $1300 \mathrm{rpm}$ was measured using an oscilloscope, as shown in Figure 15a. From the comparison in Figure 15b, we can find that phase $A$ back-EMF voltages of the prototype and the FEM were very similar under the no-load condition. The FPM allowed FEM to calculate the back-EMF with the magnetic saturation level of the rated-load condition. Hence, its result was slightly lagging and distorted compared to the back-EMF waveforms at no-load condition.

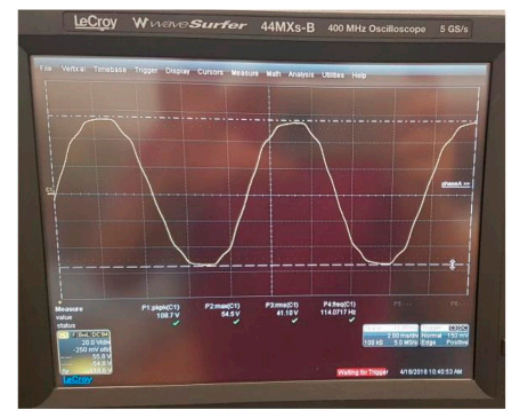

(a)

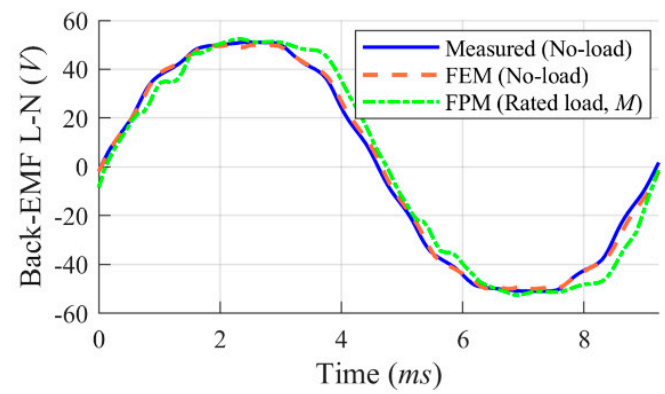

(b)

Figure 15. (a) Measured line-to-neutral back-EMF voltage of phase $A$ for the prototype using an oscilloscope. (b) Comparison of the phase $A$ back-EMF obtained from the no-load measurement, no-load FEM, and FPM with excitation of magnet-only.

It was difficult to isolate different torque components of an IPM machine and measure them separately. In practice, only cogging torque at no-load condition could be measured independently. Therefore, the measured no-load cogging torque was compared with the results of the FEM and the six-time FPM in Figure 16. According to Figure 16, the measured cogging torque had good consistency with the FEM results when there was no current excitation. This shows that the FEM was quite accurate for predicting the cogging torque ripples at no-load, low saturation conditions. The six-time FPM considered the saturation effect caused by current excitation at the rated-load condition, and hence, the cogging torque under this condition was distorted. In addition, only the FPM calculated cogging toque had an obvious DC offset; the cogging torques obtained from the no-load FEM and experimental measurement under no-load has zero average value. This confirms the assumption made in Section 3.2.2 that the DC offset in the FPM calculated cogging torque was caused by the saturation effect at loaded conditions. At the rated load condition, an extra harmonic appears to the cogging torque, as shown in Figure 17a. This 1st order harmonic caused the uneven amplitude of the cogging torque ripples. Although the loading conditions were different, the cogging torque calculated using six-time FPM still had the same frequency, similar phase position, and similar 2nd order torque 
ripple amplitude with the experimental results. The comparison with the experimental results in Figures 14-17 confirmed that magnetic saturation caused additional harmonics in the overall torque, cogging torque, and magnet flux linkage. The phase relation of these additional harmonics played a significant role in the reduction of overall torque ripple of spoke-type FSCW IPM machines.

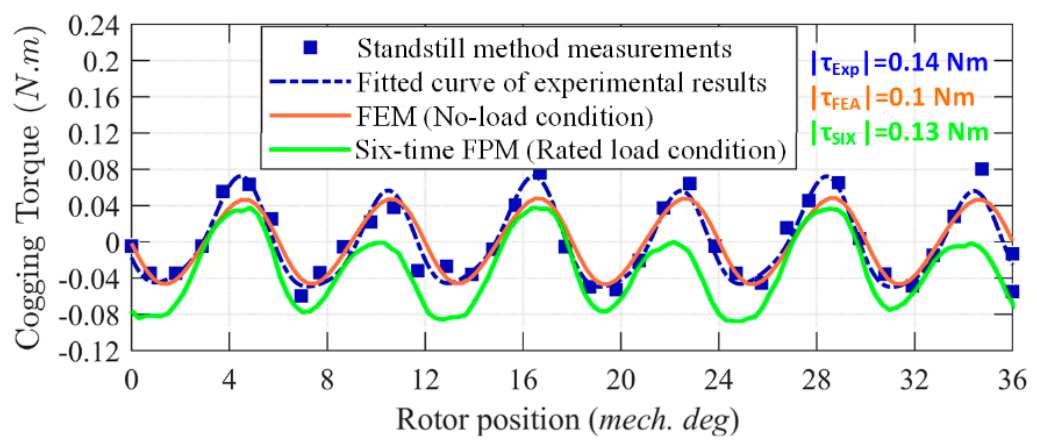

Figure 16. Comparison of the cogging torque obtained from experimental measurements with the FEM and six-time FPM results.

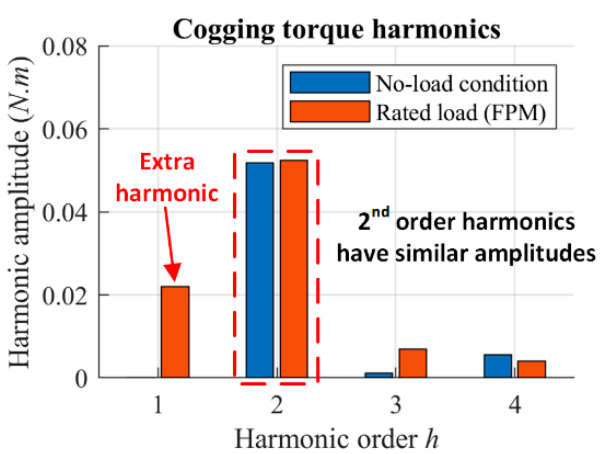

(a)

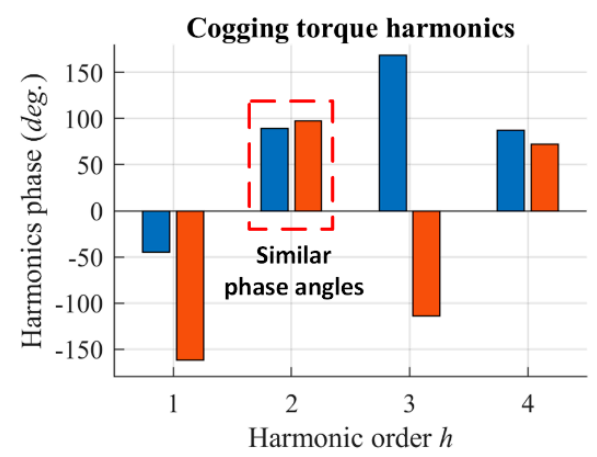

(b)

Figure 17. Comparison of cogging torques at no-load and rated-load conditions: (a) harmonic amplitudes, (b) harmonic phase angles.

\section{Conclusions}

This paper analyzed an optimized I-type FSCW IPM machine to understand the underlying electromagnetic effects for producing considerably low torque ripples. The six steps frozen permeability method (six-time FPM) was employed in the FEM to separate various torque components from the overall torque. The key torque components were categorized as the magnet torque, the reluctance torque, the torque components caused by cross-magnetization, and the cogging torque. In addition, the $d-, q$-axes components of the magnet flux linkages calculated from the separated torque components were found to be more accurate for reproducing torque ripples of the magnet torque. The accuracy of the proposed torque component separation method was verified using FEM and experimental measurements. Experimental results confirmed that: (1) the six-time FPM based torque separation method is fairly accurate for analyzing the torque ripples; (2) the torque ripple cancellation phenomenon found from finite element simulation is achieved by the real motor prototype; (3) at loaded conditions, the magnetic saturation could cause additional harmonics in the overall torque, cogging torque, back EMF and magnet flux linkage.

It can be concluded from the analysis that in the optimized spoke-type FSCW IPM machine, the sum of the magnet and reluctance torque ripples are oppositely in-phase to the sum of the rest torque components resulting in a significant reduction of the overall ripple. The geometric parameter such as magnet width and the slot opening have influences on both the magnitude and the phase relations of the torque ripple harmonics. Hence, optimization of these two parameters is essential to obtain low torque ripple in the design of a spoke-type FSCW IPM machine. In addition, for the design of FSCW 
I-type machines, a general guideline we found from this study is that increasing the slot-opening could reduce the magnetic torque ripple amplitude. Magnetic torque is normally the major torque component of a permanent magnet machine. Increasing the slot-opening width reduces the torque ripple but also decreases the average torque. As a result of this confliction, there exists an optimum slot-opening width value at which we can achieve the lowest torque ripple without sacrificing the torque density. This is contradictory to the conventional belief of distributed winding in which smaller the slot-opening lower the torque ripple. This finding is true for most FSCW I-type motor designs, and hence, can be used by machine designers to determine slot-opening width at the initial design stage using FEM parametric swiping. Future works will be performed in attempts to find a general solution and the analytical model for producing the optimum torque ripple cancellation for different motor configurations.

Author Contributions: Conceptualization, R.D.; methodology, G.C. and A.P.; software, G.C.; validation, G.C. and A.P.; formal analysis, G.C.; investigation, G.C.; data curation, G.C.; writing-original draft preparation, G.C.; writing-review and editing, R.D.; visualization, G.C.; supervision, R.D. and M.F.R.; project administration, R.D. and M.F.R.; funding acquisition, R.D. All authors have read and agreed to the published version of the manuscript.

Funding: This research was funded by Australian Research Council's Discovery Projects Funding Scheme, grant number DP170102288.

Conflicts of Interest: The authors declare no conflict of interest. The funders had no role in the design of the study; in the collection, analyses, or interpretation of data; in the writing of the manuscript, or in the decision to publish the results.

\section{References}

1. Yang, Z.; Shang, F.; Brown, I.P.; Krishnamurthy, M. Comparative Study of Interior Permanent Magnet, Induction, and Switched Reluctance Motor Drives for EV and HEV Applications. IEEE Trans. Transp. Electrif. 2015, 1, 245-254. [CrossRef]

2. Zheng, P.; Wang, W.N.; Wang, M.Q.; Liu, Y.; Fu, Z.X. Investigation of the Magnetic Circuit and Performance of Less-Rare-Earth Interior Permanent-Magnet Synchronous Machines Used for Electric Vehicles. Energies 2017, 10, 2173. [CrossRef]

3. Gu, W.W.; Zhu, X.Y.; Quan, L.; Du, Y. Design and Optimization of Permanent Magnet Brushless Machines for Electric Vehicle Applications. Energies 2015, 8, 13996-14008. [CrossRef]

4. Dorrell, D.G.; Hsieh, M.F.; Knight, A.M. Alternative Rotor Designs for High Performance Brushless Permanent Magnet Machines for Hybrid Electric Vehicles. IEEE Trans. Magn. 2012, 48, 835-838. [CrossRef]

5. Zhao, W.L.; Lipo, T.A.; Kwon, B.I. Torque Pulsation Minimization in Spoke-type Interior Permanent Magnet Motors With Skewing and Sinusoidal Permanent Magnet Configurations. IEEE Trans. Magn. 2015, 51, 1. [CrossRef]

6. Pouramin, A.; Dutta, R.; Rahman, M.F. Design Optimization of a Spoke-Type FSCW IPM Machine to Achieve Low Torque Ripple and High Torque Density under a Wide Constant Power Speed Range. In Proceedings of the 2018 IEEE Energy Conversion Congress and Exposition (ECCE), Portland, OR, USA, 23-27 September 2018; pp. 6914-6921.

7. Hwang, K.Y.; Jo, J.H.; Kwon, B.I. A Study on Optimal Pole Design of Spoke-Type IPMSM With Concentrated Winding for Reducing the Torque Ripple by Experiment Design Method. IEEE Trans. Magn. 2009, 45, 4712-4715. [CrossRef]

8. Bianchi, N.; Bolognani, S.; Pre, M.D.; Grezzani, G. Design considerations for fractional-slot winding configurations of synchronous machines. ITIA 2006, 42, 997-1006. [CrossRef]

9. Carraro, E.; Bianchi, N.; Zhang, S.; Koch, M. Performance Comparison of Fractional Slot Concentrated Winding Spoke Type Synchronous Motors with Different Slot-Pole Combinations. In Proceedings of the 2015 IEEE Energy Conversion Congress and Exposition (ECCE), Montreal, QC, Canada, 20-24 September 2015; pp. 6067-6074.

10. Artetxe, G.; Paredes, J.; Prieto, B.; Martinez-Iturralde, M.; Elosegui, I. Optimal Pole Number and Winding Designs for Low Speed-High Torque Synchronous Reluctance Machines. Energies 2018, 11, 128. [CrossRef]

11. El-Refaie, A.M.; Jahns, T.M. Optimal flux weakening in surface PM machines using fractional-slot concentrated windings. ITIA 2005, 41, 790-800. [CrossRef] 
12. Pouramin, A.; Dutta, R.; Rahman, M.F. Preliminary Study on Differences in the Performance Characteristics of Concentrated and Distributed Winding IPM Machines with Different Rotor Topologies. In Proceedings of the 2017 IEEE Energy Conversion Congress and Exposition (ECCE), Cincinnati, OH, USA, 1-5 October 2017; pp. 3565-3570.

13. Walker, J.A.; Dorrell, D.G.; Cossar, C. Flux-linkage calculation in permanent-magnet motors using the frozen permeabilities method. IEEE Trans. Magn. 2005, 41, 3946-3948. [CrossRef]

14. Chu, W.Q.; Zhu, Z.Q. Average Torque Separation in Permanent Magnet Synchronous Machines Using Frozen Permeability. IEEE Trans. Magn. 2013, 49, 1202-1210. [CrossRef]

15. Yamazaki, K.; Kumagai, M. Torque Analysis of Interior Permanent-Magnet Synchronous Motors by Considering Cross-Magnetization: Variation in Torque Components With Permanent-Magnet Configurations. ITIE 2014, 61, 3192-3201. [CrossRef]

16. Shuto, D.; Takahashi, Y.; Fujiwara, K. Frozen Permeability Method for Magnetic Field Analysis of Permanent Magnet Motors Considering Hysteretic Property. IEEE Trans. Magn. 2019, 55, 1-4. [CrossRef]

17. Carraro, E.; Bianchi, N.; Zhang, S.; Koch, M. Design and Performance Comparison of Fractional Slot Concentrated Winding Spoke Type Synchronous Motors With Different Slot-Pole Combinations. ITIA 2018, 54, 2276-2284. [CrossRef]

18. Bauer, D.D.; Li, J.; Sandalow, D.; Telleen, P.; Wanner, B. US Department of Energy Critical Materials Strategy; US Department of Energy, 2010. Available online: https:/www.energy.gov/sites/prod/files/piprod/documents/ cms_dec_17_full_web.pdf (accessed on 21 March 2020).

19. ICSG. The World Copper Factbook 2017; ICSG: Lisbon, Portugal, 2017.

20. Ionel, D.M.; Popescu, M.; McGilp, M.I.; Miller, T.J.E.; Dellinger, S.J. Assessment of torque components in brushless permanent-magnet machines through numerical analysis of the electromagnetic field. ITIA 2005, 41, 1149-1158. [CrossRef]

21. Popescu, M.; Ionel, D.M.; Miller, T.J.E.; Dellinger, S.J.; McGilp, M.I. Improved finite element computations of torque in brushless permanent magnet motors. IEE Proc. Electr. Power Appl. 2005, 152, 271-276. [CrossRef]

22. Liu, Y.; Zhu, Z.Q.; Howe, D. Direct torque control of brushless DC drives with reduced torque ripple. ITIA 2005, 41, 599-608. [CrossRef]

23. Farshadnia, M.; Cheema, M.A.M.; Dutta, R.; Fletcher, J.E.; Rahman, M.F. Detailed Analytical Modeling of Fractional-Slot Concentrated-Wound Interior Permanent Magnet Machines for Prediction of Torque Ripple. ITIA 2017, 53, 5272-5283. [CrossRef]

24. Tangudu, J.K.; Jahns, T.M.; El-Refaie, A.M.; Zhu, Z.Q. Segregation of torque components in fractional-slot concentrated-winding interior PM machines using frozen permeability. In Proceedings of the 2009 IEEE Energy Conversion Congress and Exposition, San Jose, CA, USA, 20-24 September 2009; pp. 3814-3821.

25. Ansys Inc. ANSYS Maxwell V16 Training Manual; Ansys Inc.: Canonsburg, PA, USA, 2013.

26. Jaffar, M.Z.M.; Husain, I. FEA based Separation of Torque Components in Interior Permanent Magnet Machines. In Proceedings of the 2019 IEEE Energy Conversion Congress and Exposition (ECCE), Baltimore, MD, USA, 29 September-3 October 2019; pp. 1687-1694.

27. Pouramin, A.; Dutta, R.; Farshadnia, M.; Rahman, M.F. A Standstill Method to Measure Electromagnetically Induced Torque ripple of Permanent Magnet Synchronous Machines. IEEE Trans. Instrum. Meas. 2020. [CrossRef]

(C) 2020 by the authors. Licensee MDPI, Basel, Switzerland. This article is an open access article distributed under the terms and conditions of the Creative Commons Attribution (CC BY) license (http://creativecommons.org/licenses/by/4.0/). 